\title{
Management of Patients with Atrial Fibrillation: Specific Considerations for the Old Age
}

\author{
Laurent M. Haegeli and Firat Duru \\ Clinic of Cardiology, Cardiovascular Center, University Hospital of Zurich, Rämistrasse 100, 8091 Zurich, Switzerland \\ Correspondence should be addressed to Laurent M. Haegeli, lhaegeli@gmail.com
}

Received 6 December 2010; Revised 28 April 2011; Accepted 13 June 2011

Academic Editor: Atul Verma

Copyright ( $) 2011$ L. M. Haegeli and F. Duru. This is an open access article distributed under the Creative Commons Attribution License, which permits unrestricted use, distribution, and reproduction in any medium, provided the original work is properly cited.

\begin{abstract}
Atrial fibrillation (AF) is the commonest of all sustained arrhythmias, and most of the patients seeking medical therapy are in the elderly age group. The management of these patients is particularly difficult due to associated comorbidities. Hypertension, congestive heart failure, left ventricular hypertrophy, and coronary artery disease are often present in the elderly patient population, and therefore, antiarrhythmic drugs often fail due to side effects, proarrhythmia, or poor rhythm control. Recently, radiofrequency catheter ablation has been widely performed as an efficient therapy for recurrent, drug-refractory AF. Nevertheless, patients at old age were underrepresented in prior AF ablation trials, and the current guidelines for catheter ablation of AF recommend a noninvasive approach in the elderly patient group due to the lack of clinical data supporting ablation therapy. However, study results of our group and others are suggesting that catheter ablation is a safe and effective treatment for patients over the age of 65 years with symptomatic, drug-refractory AF, and therefore, patients should not be precluded from catheter ablation only on the basis of age. This paper discusses the pharmacological (rhythm control, rate control, and anticoagulation) and catheter management of AF in the elderly population.
\end{abstract}

\section{Introduction}

Atrial fibrillation (AF) is the commonest of all sustained arrhythmias, and its prevalence has been increasing. AF confers an important mortality and morbidity outcome from thromboembolism, stroke, heart failure, and significant impairment of quality of life $[1,2]$. The prevalence of AF is more prominent with advanced age. About 8 to $10 \%$ of people aged over 80 years are suffering from AF [3]. The median age of an AF patient is 75 years, and $70 \%$ of the AF patients are 65 to 85 years of age $[4,5]$. Within the next twenty to thirty years, the number of patients suffering from $\mathrm{AF}$ is expected to double or triple due to an increased AF incidence and aging of the populations in developed western countries (Figure 1) [5, 6].

In former days, the management of $\mathrm{AF}$ focused on preventing thromboembolism and controlling heart rate or rhythm. The risk of stroke is increased 5-fold by AF. $\mathrm{AF}$ is responsible for around $10-20 \%$ of all strokes. In patients age groups 80 to 89 years, this proportion is even more accentuated and around 25\% [7]. Strokes related to AF result often in higher mortality and morbidity rates. The use of oral anticoagulation therapy is an important intervention in preventing AF-related ischemic events. But older people have both higher risk for stroke if not taking oral anticoagulants and higher risk for bleeding with the use of oral anticoagulants [8]. Therefore, the recommendation for anticoagulation is a challenging task for the clinician treating patients with AF in the old age. Disease management is also particularly challenged by comorbidities including hypertension, congestive heart failure, left ventricular hypertrophy, coronary artery disease, and diabetes mellitus which are frequently present in this patient age group. These comorbidities also confer an increased risk for thromboembolic complications or drug-related side effects [9]. Moreover, other endpoints such as left ventricular and atrial function, quality of life, social functioning, silent cerebral embolism and dementia are novel targets of comprehensive AF disease management [10]. 


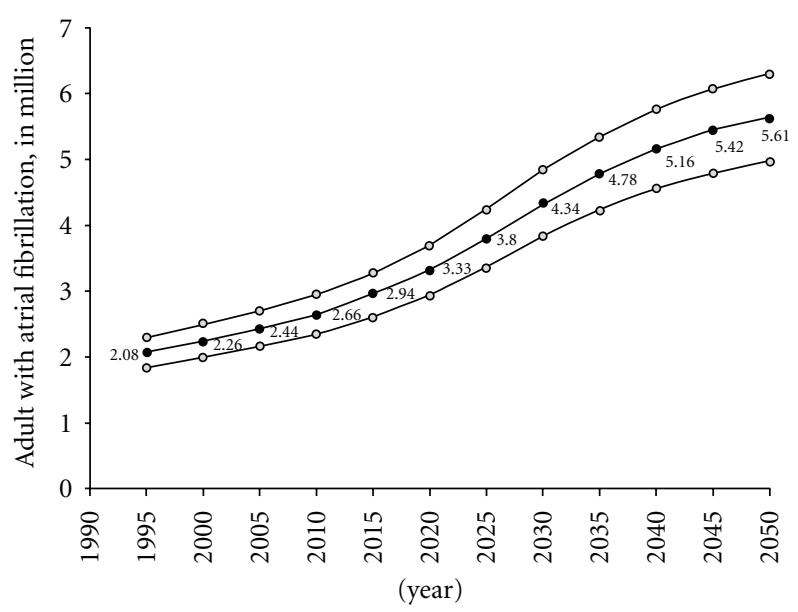

FIGURE 1: Projected number of adults with AF in the United States between 1995 and 2050 from the ATRIA study (the AnTicoagulation and Risk Factors in Atrial Fibrillation Study) [5].

Ablation therapy has emerged as an efficient intervention for recurrent, drug-refractory AF [11-14]. Current ablation techniques have improved, and the complication rates have decreased resulting in increasing number of referrals of patients of old age for catheter ablation of AF [15-18]. Nevertheless, a minority of elderly patients were included in prior AF ablation trials. Friable cardiac structures, which may be at risk for catheter perforation, long procedure times, and the associated comorbidities, are frequently considered to confer an increase of overall peri- and postprocedural risk. For that reason and in the absence of clinical data, the recommendation in the guidelines for catheter ablation of $\mathrm{AF}$ advices a conservative approach in patient populations of old age [19]. Nevertheless, with advanced life expectancy, the elderly population group is a rapidly expanding portion of our community making $\mathrm{AF}$ an even more important public health concern. Catheter ablation could become a pivotal treatment strategy in the elderly patient population after failure of antiarrhythmic drugs.

\section{Stroke Prevention in the Elderly}

Oral vitamin $\mathrm{K}$ antagonists efficiently reduce the risk of cerebrovascular embolism in elderly AF patients as clearly shown in several randomized trials [20,21]. Patients with AF aged over 75 years have a thromboembolic complication risk of over $4 \%$ per year, mandating therapy with oral vitamin $\mathrm{K}$ antagonists unless there is a significant risk for major bleeding present. Among each components of the widespread $\mathrm{CHADS}_{2}$ (cardiac failure, hypertension, age, diabetes, and stroke (doubled)) risk score, age $\geq 75$ years confers an impaired prognosis for stroke and mortality over hypertension, heart failure, or diabetes [22]. Therefore, the $\mathrm{CHADS}_{2}$ score was extended recently to the $\mathrm{CHA}_{2} \mathrm{DS}_{2}$-VASc score by considering additional risk factors such as vascular disease (i.e., prior myocardial infarction), age between 65 and 74 years, and female sex (Table 1) [23]. The risk for stroke can be reduced by oral vitamin $\mathrm{K}$ antagonists by about $70 \%$ and
TABLE 1: Stroke risk assessment in nonvalvular AF: $\mathrm{CHA}_{2} \mathrm{DS}_{2}$-VASc [23]. For a $\mathrm{CHA}_{2} \mathrm{DS}_{2}$-VASc score $>1$, such patients are high risk, and oral anticoagulation is recommended; for a $\mathrm{CHA}_{2} \mathrm{DS}_{2}$-VASc $=1$, either oral anticoagulation or apirin 75 to $325 \mathrm{mg}$ daily is recommended, but oral anticoagulation is preferred rather than aspirin; for a $\mathrm{CHA}_{2} \mathrm{DS}_{2}-\mathrm{VASc}=0$, either aspirin 75 to $325 \mathrm{mg}$ daily or no antithrombotic treatment can be used, but no antithrombotic therapy is preferred.

\begin{tabular}{lc}
\hline Risk factors & Score \\
\hline Congestive heart failure/LV dysfunction & 1 \\
Hypertension & 1 \\
Age $\geq 75$ years & 2 \\
Diabetes mellitus & 1 \\
Stroke/TIA/TE & 2 \\
Vascular disease (prior MI, PAD, or aortic plaque) & 1 \\
Age 65-74 years & 1 \\
Sex category (i.e., female sex) & 1 \\
\hline Maximum score & 9 \\
\hline
\end{tabular}

TIA: transient ischemic attack; TE: thromboembolic event.

consecutively the mortality by $33 \%$ [24]. But, these agents have a small therapeutic window with an associated hemorrhagic risk complicating anticoagulation management. In general, the anticoagulation intensity should be optimized by keeping the international normalized ratio (INR) between 2.0 and 3.0 [25]. Several studies have shown that low fixed-dose use of an oral vitamin $\mathrm{K}$ antagonist or targeting lower INRs $(<2.0)$ in older patient groups increase the risk for stroke without protecting against intracerebral bleeding [25-27]. In cases where oral vitamin $\mathrm{K}$ antagonists are contraindicated, antiplatelet therapy with aspirin provides some prevention from cerebrovascular embolism, but much less efficiently than oral vitamin $\mathrm{K}$ antagonists [28]. Aspirin reduces the risk for stroke by about $20 \%$. Interestingly, the beneficial effect of antiplatelet therapy on ischemic stroke appears to diminish with increasing age and is no longer present after the age of 77 years $[29,30]$. Warfarin was found to be superior to combined therapy with clopidogrel plus aspirin with similar rates of bleeding complications in the Atrial fibrillation Clopidogrel Trial with Irbesartan for prevention of Vascular Events (ACTIVE-W) study [31]. A novel generation of oral anticoagulants is emerging and being approved for AF such as dabigatran, an oral direct thrombin inhibitor. In a large randomized trial (Randomized Evaluation of Long-Term Anticoagulation Therapy; RE-LY), dabigatran has shown to be superior to warfarin in terms of similar reduction of stroke rates, but lower rates for major bleeding [32]. Apixaban, a novel factor Xa inhibitor, was superior to aspirin for reduction in stroke without increase of major bleeding in 5599 patients (mean age of 70 years), who are unsuitable for vitamin $\mathrm{K}$ antagonist therapy, as reported in the AVERROES trial [33]. Elderly patients are less likely than younger patients to receive appropriate anticoagulation and are more likely to have subtherapeutic INR levels. In general practice, fewer than half of eligible patients take warfarin [34, 35]. High fall risk, history of bleeding, nonadherence, and dementia are the major factors 
preventing physicians to prescribe oral anticoagulants [3638]. Therefore, in elderly patients ineligible for vitamin $\mathrm{K}$ antagonist therapy, oral direct thrombin or factor Xa inhibitor, dabigatran, or apixaban, respectively, should be considered as an effective and safe option.

\section{Pharmacological Management in the Elderly}

Several randomized trials comparing rhythm control versus rate control in $\mathrm{AF}$ patients showed no evidence that the clinical outcome of hospitalization, stroke, and mortality is improved by restoration and maintenance of sinus rhythm despite the clear relationship between AF and cardiovascular events [39-44]. Moreover, rhythm control by pharmacological interventions has been associated with higher mortality in the elderly [40]. However, subgroup analyses and the recent published outcome data of the ATHENA trial signalize that safely maintained sinus rhythm by novel antiarrhythmic drugs may prevent AF-related complications $[45,46]$. This placebo-controlled, double-blinded conducted study assessed the efficacy of dronedarone for the prevention of cardiovascular hospitalisation or death from any cause in patients with $\mathrm{AF}$ and atrial flutter. Nevertheless, apart from the effect of dronedarone on the composite endpoint driven by cardiovascular hospitalizations in the ATHENA trial, there are no controlled data available that show a benefit of rhythm control therapy beyond improved quality of life. The major studies on rhythm versus rate control were the rate control versus electrical cardioversion (RACE) trial [39], the atrial fibrillation follow-up investigation of rhythm management (AFFIRM) trial [40], and the atrial fibrillation congestive heart failure (AF-CHF) trial [43]. There was also a series of smaller studies performed, including the pharmacological intervention in atrial fibrillation (PIAF) [44], strategies of treatment of atrial fibrillation (STAF) [41], and how to treat chronic atrial fibrillation (HOT CAFÉ) [42]. These studies have shown that primary rate control is not inferior to rhythm control. Therefore, first-line therapy in the elderly patient population with symptomatic AF is usually a primary rate control approach. Betablockers, nondihydropyridine calcium channel blockers, and digoxin are widely used to control the ventricular rate response in AF [35]. Digoxin can be added if impaired left ventricular systolic function is present, but caution should be raised because of potential drug toxicity, especially in elderly patients with frequent impaired renal function and polypharmacy. Previous guidelines recommended targeting a resting heart rate of less than 80 beats per minute. But a recent randomized trial showed no clinical benefit of a strict rate control versus a lenient rate control targeting resting heart rates of about 115 beats per minute in terms of clinical cardiovascular events [47]. Antiarrhythmic drugs with the aim to maintain sinus rhythm may be considered, if patients remain symptomatic despite optimal rate control, but the increased risk for proarrhythmia, drug interactions, and agerelated comorbidities in the elderly population should be carefully taken into account. Class Ic antiarrhythmic drugs, flecainide, and propafenone have shown to increase mortality in patients with coronary artery disease [48]. Sotalol
TABLE 2: Major complication rates in a worldwide survey of catheter ablation for AF in 16,309 patients from Cappato et al. [56].

\begin{tabular}{lc}
\hline Type of complication & Rate, $\%$ \\
\hline Death & 0.15 \\
Tamponade & 1.31 \\
Pneumothorax & 0.09 \\
Hemothorax & 0.02 \\
Sepsis & 0.01 \\
Phrenic nerve palsy & 0.17 \\
Femoral pseudoaneurysm & 0.93 \\
Arteriovenous fistulae & 0.545 \\
Valve damage/requiring surgery & 0.07 \\
Atrio-esophageal fistulae & 0.04 \\
Stroke & 0.23 \\
Transient ischemic attack & 0.71 \\
PV stenoses requiring intervention & 0.29 \\
\hline Total & 4.54 \\
\hline PV: pulmonary vein.
\end{tabular}

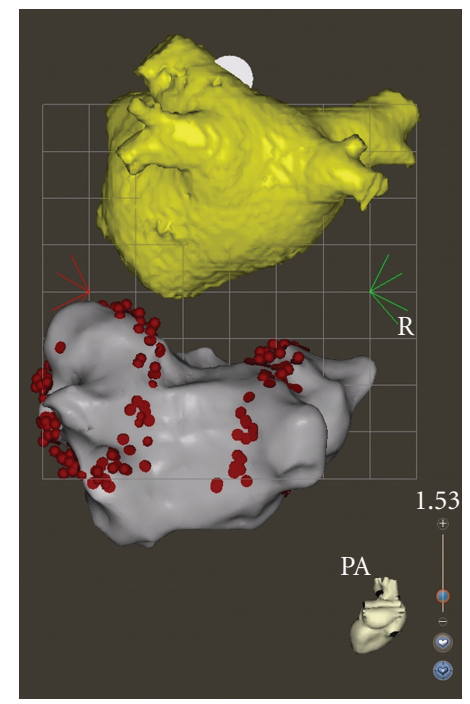

FIgURE 2: Three-dimensional reconstruction (yellow) of the computed tomography imaging and three-dimensional electroanatomical map (grey) of the left atrium in posteroanterior projection with circumferential ablation (red points) around ipsilateral pulmonary veins using CARTO system (Biosense Webster Inc., Diamond Bar, Calif, USA).

and dofetilide should not be used in patients with renal impairment. Amiodarone is the most effective drug and safe in heart failure patients, but regular follow-up of thyroid, hepatic, and pulmonary function is mandatory because of frequent extracardiac drug toxicity. Therefore, amiodarone should be reserved for use if other antiarrhythmic drugs have failed or are contraindicated.

\section{Catheter Ablation of AF in the Elderly}

An effective alternative option for drug-refractory AF with a rapid ventricular rate response is the transvenous catheter 
TABLE 3: Catheter ablation of AF in the elderly.

\begin{tabular}{|c|c|c|c|c|}
\hline & Haegeli et al. [57] & Bunch et al. [58] & Tan et al. [59] & Zado et al. [60] \\
\hline \multirow{3}{*}{ Inclusion age (years) } & \multirow{3}{*}{$\geq 65$} & \multirow{3}{*}{$\geq 80$} & $\geq 80$ & $65-74$ \\
\hline & & & $70-79$ & $\geq 75$ \\
\hline & & & $60-69$ & \\
\hline \multirow{3}{*}{ Mean age (years) } & \multirow{3}{*}{$69 \pm 3.5$} & \multirow{3}{*}{$82 \pm 2$} & $84 \pm 5$ & $68 \pm 3$ \\
\hline & & & $75 \pm 4$ & $77 \pm 2$ \\
\hline & & & $66 \pm 4$ & \\
\hline \multirow{3}{*}{ Number of patients } & \multirow{3}{*}{45} & \multirow{3}{*}{35} & 49 & 185 \\
\hline & & & 151 & 32 \\
\hline & & & 177 & \\
\hline \multirow{3}{*}{ Number of procedures } & \multirow{3}{*}{53} & \multirow{3}{*}{35} & 53 & 228 \\
\hline & & & 174 & 34 \\
\hline & & & 209 & \\
\hline \multirow{3}{*}{ Paroxysmal AF (\%) } & \multirow{3}{*}{87} & \multirow{3}{*}{46} & 55 & 62 \\
\hline & & & 53 & 53 \\
\hline & & & 51 & \\
\hline \multirow{2}{*}{ Ablation strategy } & $\mathrm{PVI} \pm$ linear & $\mathrm{PVI} \pm$ linear & PVI & PVI \\
\hline & lesions & Lesions & & \\
\hline Mean F/U (months) & 6 & 12 & 18 & 27 \\
\hline \multicolumn{5}{|l|}{ Periprocedural complication rate (\%) } \\
\hline (i) Pericardial tamponade & 1.9 & 2.8 & 0.2 & 0.4 \\
\hline (ii) Deep venous thrombosis & 0 & 2.8 & 0.9 & 0 \\
\hline (iii) CVA/TIA & 0 & 0 & 0.7 & 0.8 \\
\hline (iv) Retroperitoneal bleeding & 0 & 0 & 0.7 & 0.4 \\
\hline (v) Pseudoaneurysm/AV fistula & 030 & 0 & 0.5 & 2.7 \\
\hline \multirow{3}{*}{ Freedom of AF } & \multirow{3}{*}{$74 \%$} & \multirow{3}{*}{$78 \%$} & $70 \%$ & $84 \%$ \\
\hline & & & $72 \%$ & $86 \%$ \\
\hline & & & $74 \%$ & \\
\hline
\end{tabular}

PVI: pulmonary vein isolation; CVA: cerebral vascular accident; TIA: transient ischemic attack.

ablation of the atrioventricular node and the placement of a permanent pacemaker. The procedure is associated with minimal mortality and morbidity, but this approach does not eliminate AF and the need for anticoagulation [49]. Pathophysiological knowledge that focal sources of ectopic beats arising from the pulmonary veins often initiate AF has lead to the development of catheter ablation for AF in the last decade [11]. The majority of ablation strategies currently used involves circumferential ablation around the ostia of the ipsilateral pulmonary veins with the endpoint of electrical isolation of the pulmonary veins from the left atrium [50-52]. Success rates approach $70 \%$ to $90 \%$ in experienced centers [53]. However, most of the published data are obtained in younger patients aged below 65 years and without heart disease and comorbidities. Catheter ablation for chronic AF is less successful than for paroxysmal $\mathrm{AF}$ and is associated with higher complication rates in older patients having structural heart disease [14, 54, 55]. Procedure-related complication rates were reported in a large worldwide multicenter survey and are listed on Table 2 [17]. In a retrospective analysis of 641 consecutive ablation procedures, the rate for major complications was 5\%, and the age greater than 70 years was identified as a significant predictor with an odds ratio of 3.7 [18].

In a recently published study, we reported the clinical outcome of 45 consecutive patients over the age of 65 years who underwent a percutaneous catheter ablation procedure for symptomatic paroxysmal and persistent AF [57]. Among them, none had a significant structural heart disease. All patients underwent wide-area circumferential pulmonary vein isolation for paroxysmal AF with additional linear lesions for persistent AF. The ablation was performed point by point by radiofrequency energy and guided by a threedimensional electroanatomical mapping system (Figure 2) [61]. The endpoint of the procedure in both paroxysmal and persistent AF patients was electrical isolation of all pulmonary veins, which was assessed using a circular spiral catheter. Our results suggested that catheter ablation of AF 


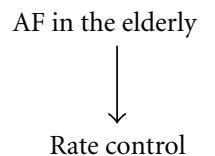

- AV node-blocking agents

- Consider AV node ablation and pacemaker implantation

for elderly patients with structure heart disease and difficult rate control

Rhythm control

\begin{tabular}{|c|c|c|}
\hline No or minimal heart disease: & Structural heart disease: & \\
\hline \multirow{3}{*}{$\begin{array}{l}\text { Dronedarone } \\
\text { Flecainide } \\
\text { Propafenone } \\
\text { Sotalol }\end{array}$} & - Heart failure NYHA I/II & Dronedarone \\
\hline & - Coronary artery disease & $\begin{array}{l}\text { Dronedarone } \\
\text { sotalol }\end{array}$ \\
\hline & - LVH & Dronedarone \\
\hline$\downarrow$ & $\begin{array}{c}\downarrow \\
\text { Amiodarone } \\
\downarrow\end{array}$ & \\
\hline & & \\
\hline
\end{tabular}

$\mathrm{AV}$, atrioventricular; NYHA, New York heart association class; LVH, left ventricular hypertrophy

FIGURE 3: Decision tree for the therapy of AF in the elderly integrating pharmacological treatment and catheter ablation, modified from the guidelines for the management of AF proposed by the European Society of Cardiology [63].

in elderly patients can be performed with success rates comparable to those in younger patients without an increase in complication rate. Successful maintenance of a stable sinus rhythm could be achieved in nearly $80 \%$ of this patient cohort with a mean age of 69 years (Table 3). Zado et al. found similar success and complication rates in patients over 65 years of age [60]. Patients over the age of 80 years in the paper of Tan et al. were less likely to undergo a repeat procedure than younger patients. However, the success and complication rates were not significantly different in the age group over 80 years than in those $60-69$ years $(70 \%$ versus $74 \%$ for success rate) [59]. Similarly, the study reported by Bunch et al. found no increased risk of periprocedural complications in patients aged 80 years and older [58]. Available published outcome data for catheter ablation in the elderly population were derived from observational cohort analysis with a follow-up period of up to two years with procedural success defined as freedom from symptomatic AF. A long-term follow-up study reported that the success rate in 100 patients was $63 \%$ at 5 years after a median of two procedures per patient [62]. Prospective, randomized trials comparing an invasive versus a conservative pharmacological approach are required to address the remaining questions on best management of AF in the elderly population. A decision tree integrating different choices of rate and rhythm control and pharmacological therapy versus catheter ablation of $\mathrm{AF}$ in this selected elderly patient population is proposed in Figure 3 based on the current guidelines of the European Society of Cardiology [63].

\section{Conclusion}

Elderly patients differ considerably from patients in the younger age group as they have a higher incidence of AF associated with a higher thromboembolic risk due to advanced age and frequent multiple comorbidities. In addition, the adverse side effects of antiarrhythmic drugs, such as proarrhythmia, are more commonly observed in the elderly patient population. Nonrandomized studies in patients aged 65 years and more with symptomatic drugrefractory AF have shown that catheter ablation can be performed with comparable safety and efficiency as with younger patients. Therefore, ablation therapy may be considered as an appropriate therapeutic option also for the older group of patients if antiarrhythmic drug treatment fails. Patients should not be precluded from undergoing AF catheter ablation exclusively on the basis of age.

\section{Conflict of Interests}

The authors declare that there is no conflict of interests.

\section{References}

[1] P. A. Wolf, R. D. Abbott, and W. B. Kannel, "Atrial fibrillation as an independent risk factor for stroke: the framingham study," Stroke, vol. 22, no. 8, pp. 983-988, 1991.

[2] J. Heeringa, D. A. van der Kuip, A. Hofman et al., "Prevalence, incidence and lifetime risk of atrial fibrillation: the Rotterdam 
study," European Heart Journal, vol. 27, no. 8, pp. 949-953, 2006.

[3] S. L. Kopecky, B. J. Gersh, M. D. McGoon et al., "The natural history of lone atrial fibrillation. A population-based study over three decades," New England Journal of Medicine, vol. 317, no. 11, pp. 669-674, 1987.

[4] W. M. Feinberg, J. L. Blackshear, A. Laupacis, R. Kronmal, and R. G. Hart, "Prevalence, age distribution, and gender of patients with atrial fibrillation: analysis and implications," Archives of Internal Medicine, vol. 155, no. 5, pp. 469-473, 1995.

[5] A. S. Go, E. M. Hylek, K. A. Phillips et al., "Prevalence of diagnosed atrial fibrillation in adults: national implications for rhythm management and stroke prevention: the anticoagulation and risk factors in atrial fibrillation (ATRIA) study," Journal of the American Medical Association, vol. 285, no. 18, pp. 2370-2375, 2001.

[6] Y. Miyasaka, M. E. Barnes, B. J. Gersh et al., "Secular trends in incidence of atrial fibrillation in Olmsted County, Minnesota, 1980 to 2000, and implications on the projections for future prevalence," Circulation, vol. 114, no. 2, pp. 119-125, 2006.

[7] K. Lakshminarayan, C. A. Solid, A. J. Collins, D. C. Anderson, and C. A. Herzog, "Atrial fibrillation and stroke in the general medicare population: a 10-year perspective (1992 to 2002)," Stroke, vol. 37, no. 8, pp. 1969-1974, 2006.

[8] R. Marinigh, G. Y. Lip, N. Fiotti, C. Giansante, and D. A. Lane, "Age as a risk factor for stroke in atrial fibrillation patients: implications for thromboprophylaxis," Journal of the American College of Cardiology, vol. 56, no. 11, pp. 827-837, 2010.

[9] A. B. Curtis and M. W. Rich, "Atrial fibrillation in the elderly: mechanisms and management," Heart Rhythm, vol. 4, no. 12, pp. 1577-1579, 2007.

[10] P. Kirchhof, J. Bax, C. Blomstrom-Lundquist et al., "Early and comprehensive management of atrial fibrillation: executive summary of the proceedings from the 2nd AFNET-EHRA consensus conference 'research perspectives in AF', European Heart Journal, vol. 30, no. 24, pp. 2969-2977, 2009.

[11] M. Haissaguerre, P. Jais, D. C. Shah et al., "Spontaneous initiation of atrial fibrillation by ectopic beats originating in the pulmonary veins," New England Journal of Medicine, vol. 339, no. 10, pp. 659-666, 1998.

[12] C. Pappone, S. Rosanio, G. Augello et al., "Mortality, morbidity, and quality of life after circumferential pulmonary vein ablation for atrial fibrillation: outcomes from a controlled nonrandomized long-term study," Journal of the American College of Cardiology, vol. 42, no. 2, pp. 185-197, 2003.

[13] H. Oral, A. Chugh, E. Good et al., "A tailored approach to catheter ablation of paroxysmal atrial fibrillation," Circulation, vol. 113, no. 15, pp. 1824-1831, 2006.

[14] H. Oral, C. Pappone, A. Chugh et al., "Circumferential pulmonary-vein ablation for chronic atrial fibrillation," New England Journal of Medicine, vol. 354, no. 9, pp. 934-941, 2006.

[15] R. Cappato, H. Calkins, S. A. Chen et al., "Worldwide survey on the methods, efficacy, and safety of catheter ablation for human atrial fibrillation," Circulation, vol. 111, no. 9, pp. 1100-1105, 2005.

[16] E. Bertaglia, F. Zoppo, C. Tondo et al., "Early complications of pulmonary vein catheter ablation for atrial fibrillation: a multicenter prospective registry on procedural safety," Heart Rhythm, vol. 4, no. 10, pp. 1265-1271, 2007.

[17] R. Cappato, H. Calkins, S. A. Chen et al., "Prevalence and causes of fatal outcome in catheter ablation of atrial fibrillation," Journal of the American College of Cardiology, vol. 53, no. 19, pp. 1798-1803, 2009.
[18] D. D. Spragg, D. Dalal, A. Cheema et al., "Complications of catheter ablation for atrial fibrillation: incidence and predictors," Journal of Cardiovascular Electrophysiology, vol. 19, no. 6, pp. 627-631, 2008.

[19] H. Calkins, J. Brugada, D. L. Packer et al., "Hrs/ehra/ecas expert consensus statement on catheter and surgical ablation of atrial fibrillation: Recommendations for personnel, policy, procedures and follow-up. A report of the heart rhythm society (hrs) task force on catheter and surgical ablation of atrial fibrillation," Heart Rhythm, vol. 4, no. 6, pp. 816-861, 2007.

[20] Laupacis, "Risk factors for stroke and efficacy of antithrombotic therapy in atrial fibrillation: analysis of pooled data from five randomized controlled trials," Archives of Internal Medicine, vol. 154, no. 13, pp. 1449-1457, 1994.

[21] R. G. Hart, O. Benavente, R. McBride, and L. A. Pearce, "Antithrombotic therapy to prevent stroke in patients with atrial fibrillation: a meta-analysis," Annals of Internal Medicine, vol. 131, no. 7, pp. 492-501, 1999.

[22] B. F. Gage, A. D. Waterman, W. Shannon, M. Boechler, M. W. Rich, and M. J. Radford, "Validation of clinical classification schemes for predicting stroke: results from the national registry of atrial fibrillation," Journal of the American Medical Association, vol. 285, no. 22, pp. 2864-2870, 2001.

[23] G. Y. Lip, R. Nieuwlaat, R. Pisters, D. A. Lane, and H. J. Crijns, "Refining clinical risk stratification for predicting stroke and thromboembolism in atrial fibrillation using a novel risk factor-based approach: the Euro Heart Survey on atrial fibrillation," Chest, vol. 137, no. 2, pp. 263-272, 2010.

[24] E. M. Hylek, A. S. Go, Y. Chang et al., "Effect of intensity of oral anticoagulation on stroke severity and mortality in atrial fibrillation," New England Journal of Medicine, vol. 349, no. 11, pp. 1019-1026, 2003.

[25] E. M. Hylek, S. J. Skates, M. A. Sheehan, and D. E. Singer, "An analysis of the lowest effective intensity of prophylactic anticoagulation for patients with nonrheumatic atrial fibrillation," New England Journal of Medicine, vol. 335, no. 8, pp. 540-546, 1996.

[26] R. McBride, "Patients with nonvalvular atrial fibrillation at low risk of stroke during treatment with aspirin: stroke prevention in atrial fibrillation III study. The spaf iii writing committee for the stroke prevention in atrial fibrillation investigators," Journal of the American Medical Association, vol. 279, no. 16, pp. 1273-1277, 1998.

[27] M. C. Fang, Y. Chang, E. M. Hylek et al., "Advanced age, anticoagulation intensity, and risk for intracranial hemorrhage among patients taking warfarin for atrial fibrillation," Annals of Internal Medicine, vol. 141, no. 10, pp. 745-752, 2004.

[28] C. van Walraven, R. G. Hart, D. E. Singer et al., "Oral anticoagulants vs aspirin in nonvalvular atrial fibrillation: an individual patient meta-analysis," Journal of the American Medical Association, vol. 288, no. 19, pp. 2441-2448, 2002.

[29] M. Hughes and G. Y. Lip, "Stroke and thromboembolism in atrial fibrillation: a systematic review of stroke risk factors, risk stratification schema and cost effectiveness data," Thrombosis and Haemostasis, vol. 99, no. 2, pp. 295-304, 2008.

[30] R. G. Hart, L. A. Pearce, G. W. Albers et al., "Independent predictors of stroke in patients with atrial fibrillation: a systematic review," Neurology, vol. 69, no. 6, pp. 546-554, 2007.

[31] S. Connolly, J. Pogue, R. Hart et al., "Clopidogrel plus aspirin versus oral anticoagulation for atrial fibrillation in the atrial fibrillation clopidogrel trial with irbesartan for prevention of 
vascular events (active w): a randomised controlled trial," The Lancet, vol. 367, no. 9526, pp. 1903-1912, 2006.

[32] S. J. Connolly, M. D. Ezekowitz, S. Yusuf et al., "Dabigatran versus warfarin in patients with atrial fibrillation," New England Journal of Medicine, vol. 361, no. 12, pp. 1139-1151, 2009.

[33] S. J. Connolly, J. Eikelboom, C. Joyner et al., "Apixaban in patients with atrial fibrillation," New England Journal of Medicine, vol. 364, no. 9, pp. 806-817, 2011.

[34] D. McCormick, J. H. Gurwitz, R. J. Goldberg et al., "Prevalence and quality of warfarin use for patients with atrial fibrillation in the long-term care setting," Archives of Internal Medicine, vol. 161, no. 20, pp. 2458-2463, 2001.

[35] M. C. Fang, R. S. Stafford, J. N. Ruskin, and D. E. Singer, "National trends in antiarrhythmic and antithrombotic medication use in atrial fibrillation," Archives of Internal Medicine, vol. 164, no. 1, pp. 55-60, 2004.

[36] T. J. Bungard, W. A. Ghali, K. K. Teo, F. A. McAlister, and R. T. Tsuyuki, "Why do patients with atrial fibrillation not receive warfarin?" Archives of Internal Medicine, vol. 160, no. 1, pp. 41-46, 2000.

[37] J. Monette, J. H. Gurwitz, P. A. Rochon, and J. Avorn, "Physician attitudes concerning warfarin for stroke prevention in atrial fibrillation: results of a survey of long-term care practitioners," Journal of the American Geriatrics Society, vol. 45, no. 9, pp. 1060-1065, 1997.

[38] P. J. Devereaux, D. R. Anderson, M. J. Gardner et al., "Differences between perspectives of physicians and patients on anticoagulation in patients with atrial fibrillation: observational study," British Medical Journal, vol. 323, no. 7323, pp. 1218-1221, 2001.

[39] I. C. Van Gelder, V. E. Hagens, H. A. Bosker et al., "A comparison of rate control and rhythm control in patients with recurrent persistent atrial fibrillation," New England Journal of Medicine, vol. 347, no. 23, pp. 1834-1840, 2002.

[40] D. G. Wyse, A. L. Waldo, J. P. DiMarco et al., "A comparison of rate control and rhythm control in patients with atrial fibrillation," New England Journal of Medicine, vol. 347, no. 23, pp. 1825-1833, 2002.

[41] J. Carlsson, S. Miketic, J. Windeler et al., "Randomized trial of rate-control versus rhythm-control in persistent atrial fibrillation: the strategies of treatment of atrial fibrillation (STAF) study," Journal of the American College of Cardiology, vol. 41, no. 10, pp. 1690-1696, 2003.

[42] G. Opolski, A. Torbicki, D. A. Kosior et al., "Rate control vs rhythm control in patients with nonvalvular persistent atrial fibrillation: the results of the Polish how to treat chronic atrial fibrillation (hot cafe) study," Chest, vol. 126, no. 2, pp. 476486, 2004.

[43] D. Roy, M. Talajic, S. Nattel et al., "Rhythm control versus rate control for atrial fibrillation and heart failure," New England Journal of Medicine, vol. 358, no. 25, pp. 2667-2677, 2008.

[44] S. H. Hohnloser, K. H. Kuck, and J. Lilienthal, "Rhythm or rate control in atrial fibrillation-pharmacological intervention in atrial fibrillation (PIAF): a randomised trial," The Lancet, vol. 356, no. 9244, pp. 1789-1794, 2000.

[45] S. D. Corley, A. E. Epstein, J. P. DiMarco et al., "Relationships between sinus rhythm, treatment, and survival in the atrial fibrillation follow-up investigation of rhythm management (AFFIRM) study," Circulation, vol. 109, no. 12, pp. 1509-1513, 2004.

[46] S. H. Hohnloser, H. J. Crijns, M. Van Eickels et al., "Effect of dronedarone on cardiovascular events in atrial fibrillation,"
New England Journal of Medicine, vol. 360, no. 7, pp. 668-678, 2009.

[47] I. C. Van Gelder, H. F. Groenveld, H. J. G. M. Crijns et al., "Lenient versus strict rate control in patients with atrial fibrillation," New England Journal of Medicine, vol. 362, no. 15, pp. 1363-1373, 2010.

[48] D. S. Echt, P. R. Liebson, L. B. Mitchell et al., "Mortality and morbidity in patients receiving encainide, flecainide, or placebo. The cardiac arrhythmia suppression trial," New England Journal of Medicine, vol. 324, no. 12, pp. 781-788, 1991.

[49] C. Ozcan, A. Jahangir, P. A. Friedman et al., "Long-term survival after ablation of the atrioventricular node and implantation of a permanent pacemaker in patients with atrial fibrillation," New England Journal of Medicine, vol. 344, no. 14, pp. 1043-1051, 2001.

[50] O. M. Wazni, N. F. Marrouche, D. O. Martin et al., "Radiofrequency ablation vs antiarrhythmic drugs as first-line treatment of symptomatic atrial fibrillation: a randomized trial," Journal of the American Medical Association, vol. 293, no. 21, pp. 2634-2640, 2005.

[51] T. Arentz, L. Haegeli, P. Sanders et al., "High-density mapping of spontaneous pulmonary vein activity initiating atrial fibrillation in humans," Journal of Cardiovascular Electrophysiology, vol. 18, no. 1, pp. 31-38, 2007.

[52] L. M. Haegeli, E. Kotschet, J. Byrne et al., "Cardiac injury after percutaneous catheter ablation for atrial fibrillation," Europace, vol. 10, no. 3, pp. 273-275, 2008.

[53] C. Pappone, H. Oral, V. Santinelli et al., "Atrio-esophageal fistula as a complication of percutaneous transcatheter ablation of atrial fibrillation," Circulation, vol. 109, no. 22, pp. 27242726, 2004.

[54] M. S. Chen, N. F. Marrouche, Y. Khaykin et al., "Pulmonary vein isolation for the treatment of atrial fibrillation in patients with impaired systolic function," Journal of the American College of Cardiology, vol. 43, no. 6, pp. 1004-1009, 2004.

[55] L. M. Haegeli, F. Duru, E. E. Lockwood et al., "Feasibility and safety of outpatient radiofrequency catheter ablation procedures for atrial fibrillation," Postgraduate Medical Journal, vol. 86, no. 1017, pp. 395-398, 2010.

[56] R. Cappato, H. Calkins, S. A. Chen et al., "Updated worldwide survey on the methods, efficacy, and safety of catheter ablation for human atrial fibrillation," Circulation, vol. 3, no. 1, pp. 32$38,2010$.

[57] L. M. Haegeli, F. Duru, E. E. Lockwood et al., "Ablation of atrial fibrillation after the retirement age: considerations on safety and outcome," Journal of Interventional Cardiac Electrophysiology, vol. 28, no. 3, pp. 193-197, 2010.

[58] T. J. Bunch, J. P. Weiss, B. G. Crandall et al., "Long-term clinical efficacy and risk of catheter ablation for atrial fibrillation in octogenarians," Pace-Pacing and Clinical Electrophysiology, vol. 33, no. 2, pp. 146-152, 2010.

[59] H. W. Tan, X. H. Wang, H. F. Shi et al., "Efficacy, safety and outcome of catheter ablation for atrial fibrillation in octogenarians," International Journal of Cardiology, vol. 145, no. 1, pp. 147-148, 2010.

[60] E. Zado, D. J. Callans, M. Riley et al., "Long-term clinical efficacy and risk of catheter ablation for atrial fibrillation in the elderly," Journal of Cardiovascular Electrophysiology, vol. 19, no. 6, pp. 621-626, 2008.

[61] L. M. Haegeli, F. Duru, and T. F. Lüscher, "Moderne technologien in der ablation des vorhofflimmerns," Cardiovascular Medicine, vol. 13, pp. 272-280, 2010. 
[62] R. Weerasooriya, P. Khairy, J. Litalien et al., "Catheter ablation for atrial fibrillation: are results maintained at 5 years of follow-up?" Journal of the American College of Cardiology, vol. 57, no. 2, pp. 160-166, 2011.

[63] A. J. Camm, P. Kirchhof, G. Y. Lip et al., "Guidelines for the management of atrial fibrillation: the task force for the management of atrial fibrillation of the European Society of Cardiology (ESC)," European Heart Journal, vol. 31, pp. 23692429, 2010. 


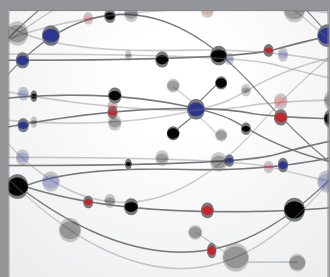

The Scientific World Journal
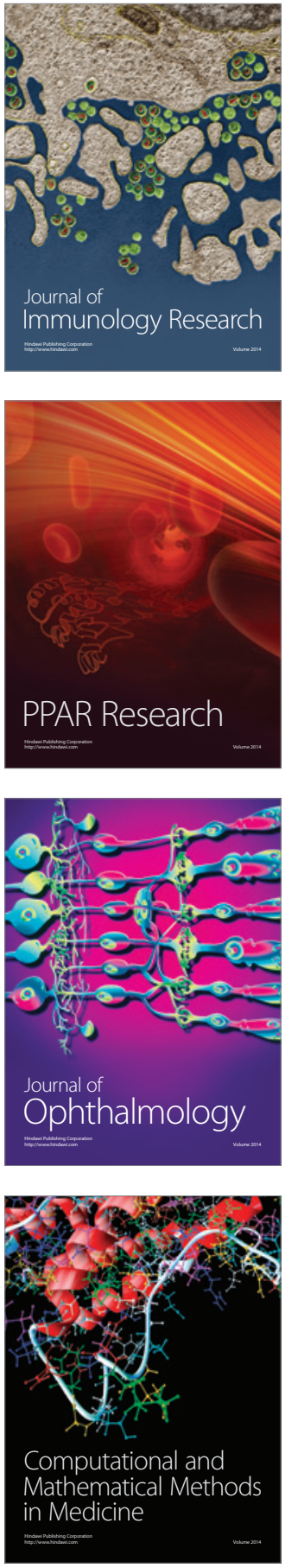

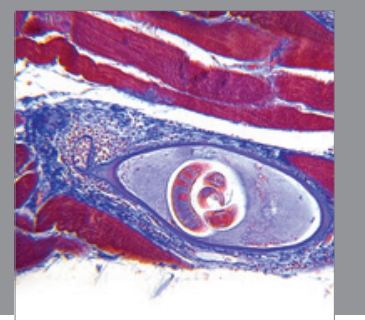

Gastroenterology

Research and Practice
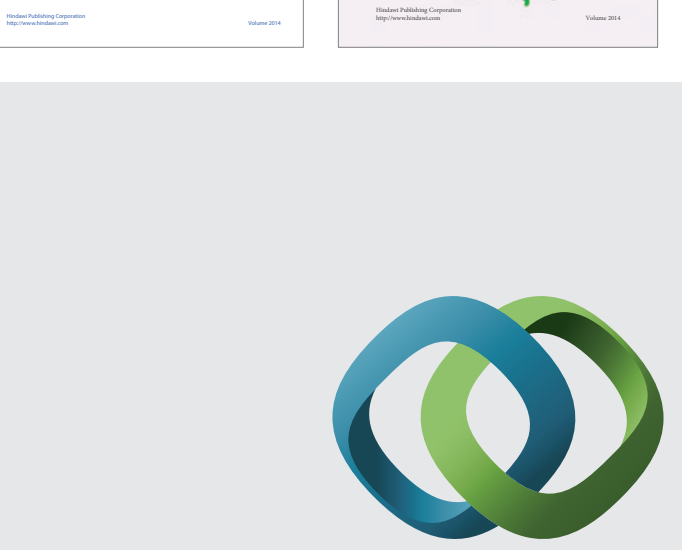

\section{Hindawi}

Submit your manuscripts at

http://www.hindawi.com
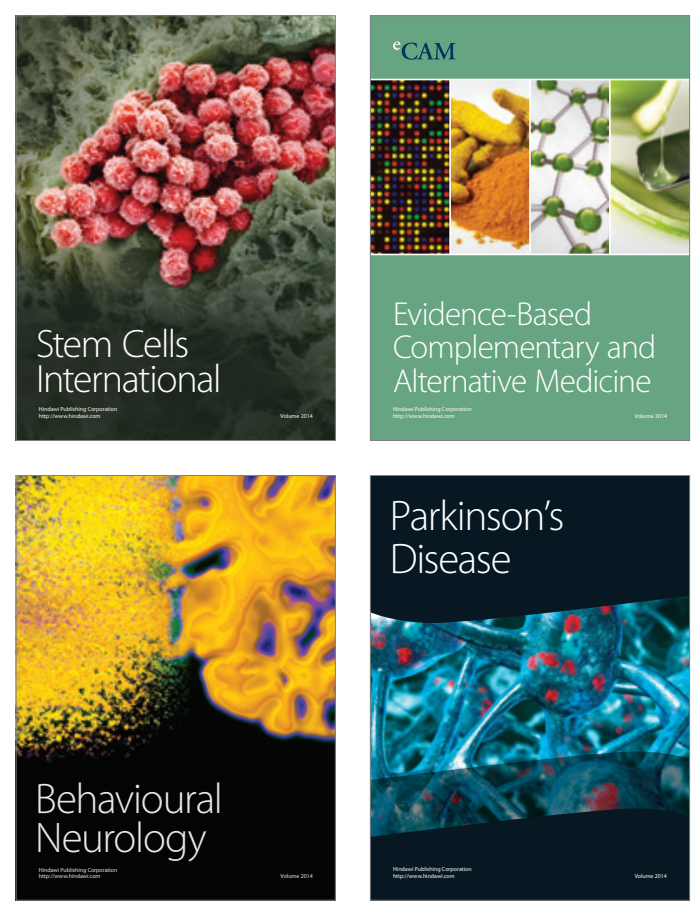

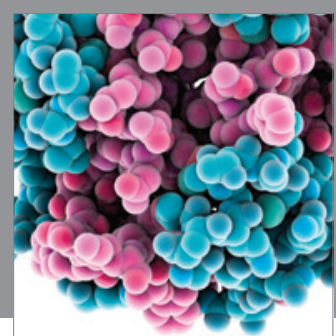

Journal of
Diabetes Research

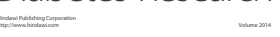

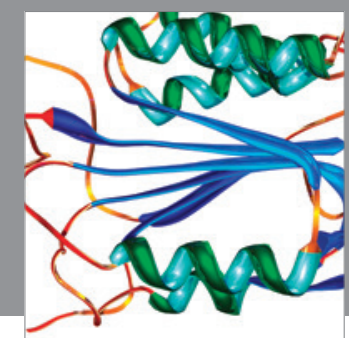

Disease Markers
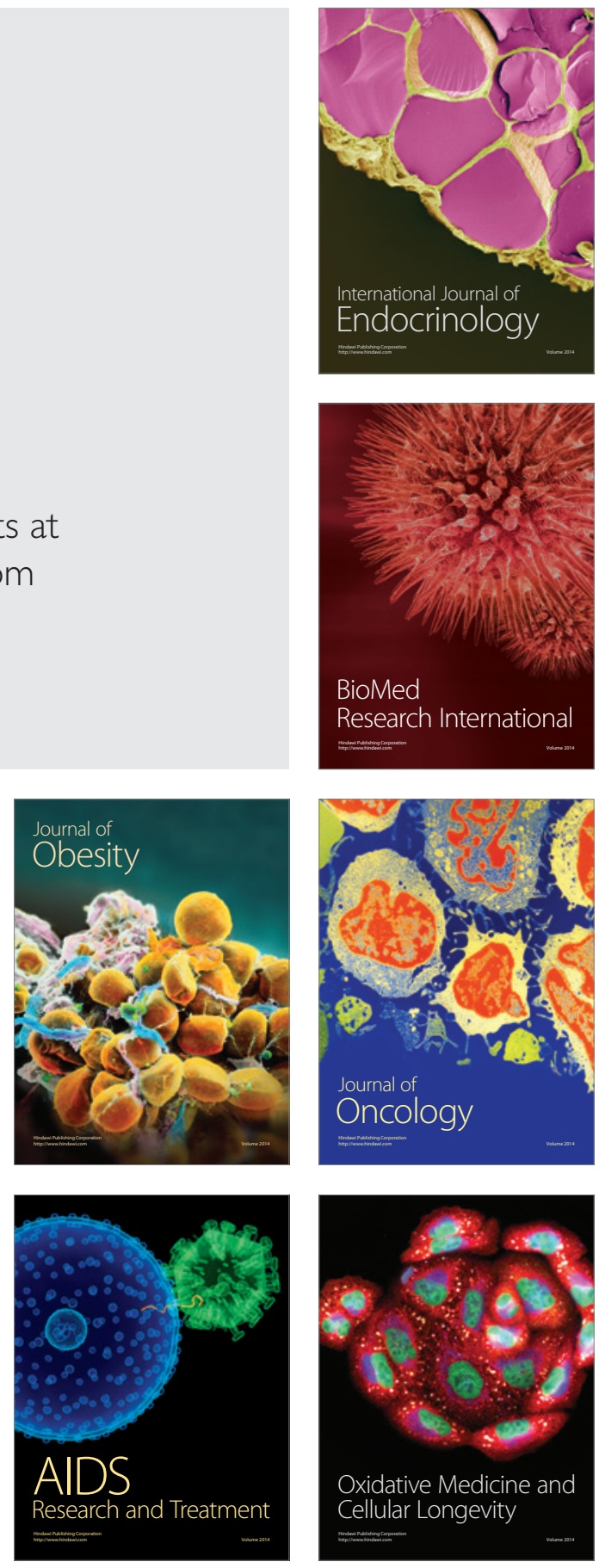